\title{
Research Review on Kindergarten Curriculum Gamification in China
}

\author{
Yuan Qiu \\ College of Education Science, Gannan Normal University, Ganzhou, China \\ Email: 13824577584@163.com
}

How to cite this paper: Qiu, Y. (2019) Research Review on Kindergarten Curriculum Gamification in China. Open Access Library Journal, 6: e5934.

https://doi.org/10.4236/oalib.1105934

Received: November 18, 2019

Accepted: November 30, 2019

Published: December 3, 2019

Copyright (C) 2019 by author(s) and Open Access Library Inc.

This work is licensed under the Creative Commons Attribution International License (CC BY 4.0).

http://creativecommons.org/licenses/by/4.0/

\section{cc) (i) Open Access}

\begin{abstract}
In recent years, the reform of kindergarten curriculum has set off a wave in China, and the kindergarten curriculum gamification has become one of the hot topics in the field of preschool education research in China. A review of the relevant research results on the gamification of kindergarten curriculum in China can further explore the research status of this field, which has important implications for the future research and development of kindergarten curriculum in China. The research shows that the research on the gamification of kindergarten curriculum in China mainly focuses on five aspects, namely, the research on the basic connotation, essential characteristics, educational value, existing difficulties and promotion strategies of the gamification of kindergarten curriculum. Finally, based on the analysis of the research results, this paper puts forward the shortcomings of the existing research and the prospect of the future research on the gamification of kindergarten curriculum.
\end{abstract}

\section{Subject Areas}

Education

\section{Keywords}

China, Kindergarten Curricula Gamification, Research Review, Future Expectations

\section{Introduction}

At present, with the turn of social contradictions and the improvement of people's living standards, the quality of preschool education is also increasingly demanding. As a basic activity for children, games are an important form of education for children's preliminary and comprehensive development. Gamifi- 
cation of kindergarten curriculum is not only the key and entry point to improve the quality of preschool education, but also the breakthrough point for the reform and construction of preschool education curriculum.

In 1979, "Urban Kindergarten Work Regulations" (Trial Draft) issued by the Ministry of Education of the People's Republic of China (Ministry of Education, PRC) first mentioned that games were basic activities for children. Subsequently, "Kindergarten Education Outline" (Trial Draft) formulated by the Ministry of Education, PRC in 1980 clearly emphasized the active development of game activities in kindergartens. However, it was officially mentioned in "Kindergarten Work Regulations (Trial)" issued by the National Education Commission of the People's Republic of China in 1989 that games should be regarded as the basic activities of children in kindergarten. Since then, the issued one after another that "Kindergarten Management Regulations" (1989), "Suggestions on Improving and Strengthening Preschool Management" (1991), "Guidelines for the Guidance of Kindergarten Education (Trial)" (2001), "Several Opinions of the State Council on Current Development of Preschool Education" (2010), "Notice of the Ministry of Education on Regulating Kindergarten Conservation Education to Prevent and Correct the Phenomenon of "Primary Schoop" (2011), "Guide to Learning and Development for Children 3 - 6 Years" (2012) (hereinafter referred to as the "Guide"), "Kindergarten Work Regulations" (2016), "Circular of the State Council on the Issuance of the 13th Five-Year Plan for the Development of National Education" (2017) and "Some Opinions on Deepening Reform and Normative Development of Preschool Education" (2018) have all clearly stipulated that kindergartens should take games as their basic activities. "Curriculum Gamification" was formally put forward after the publication of "Guide". Since then, the idea of attaching importance to the unique value brought by games to children's growth and taking games as children's basic activities has been deeply rooted in people's hearts and put into practice. In this study, the existing studies of kindergarten curriculum gamification in China were roughly sorted out and summarized, in order to understand the study status of kindergarten curriculum gamification more objectively and comprehensively.

\section{Research Data}

Data of "research on kindergarten curriculum gamification in China" in this study were extracted from China National Knowledge Infrastructure (CNKI), and 345 literatures were retrieved by using "literature $\rightarrow$ advanced search" and taking title "curriculum" + title "gamification" as the retrieval condition. After screening the literatures and excluding the literatures unrelated to the research (such as: meeting notice, no author, call for papers, interview, event promotion, kindergarten introduction, etc.), 341 valid literatures were obtained, including 10 master's theses and 6 core theses. On this basis, 125 results were obtained by taking the title "kindergarten curriculum gamification" as the retrieval condi- 
tion, and 122 valid literatures were obtained after screening, including 2 core ones. The search date was September 30, 2019.

\section{Research Results and Analysis}

By analyzing, sorting out and summarizing the related studies of kindergarten curriculum gamification in China, which can divide them into five aspects, including the studies on the basic connotation, basic characteristics, educational value, existing difficulties and promotion strategies of kindergarten curriculum gamification.

\subsection{Study on the Basic Connotation of Gamification in Kindergarten Curriculum}

There are different opinions among Chinese scholars about the basic connotation of kindergarten curriculum gamification which have no specific definition. Yu, Y. P. (2015) believed that the so-called kindergarten curriculum gamification is to make the kindergarten course setting closer to children's daily life and more suitable for their physical and mental development, so as to make the curriculum more vivid and interesting and more conducive to children's all-round development [1]. Shuai, J. R. (2016) and Song, M. (2018) both indicated that curriculum gamification should be child-oriented and fully respect the child's dominant position. The former shows that curriculum gamification uses the game as the carrier to achieve the organic integration of curriculum objectives and curriculum conditions through the game, focusing on the interaction between the children and the surrounding things, fully reflecting the child's dominant position [2]. The latter believes that curriculum gamification is different from gamification course. It is a return to the spirit of the game. It emphasizes that the spirit of the game and the experience of the game are always throughout the course, ensuring that children have sufficient game time and have the right to speak in the game [3]. Furthermore, Zhu, Z. H. (2018) from a practical point of view to thinks that curriculum gamification is a concept, an action, and more a value-oriented rather than a curriculum model, its core lies in the curriculum, which aims to make the curriculum more interesting, more suitable for young children, the ultimate goal is for the development of young children [4]. In addition, Sun, B. (2017) believes that kindergarten curriculum gamification is a teaching strategy that integrates the spirit of the game and the concept of the game into the teaching activities, which is conducive to the development of children's physical and mental pleasure [5]. And Zhang, Z. Z. (2018) understands curriculum gamification as a child's activity in kindergarten, even the all links throughout the routine [6].

Scholars have different opinions about these concepts description about the kindergarten curriculum gamification, but they all emphasize that curriculum gamification is not a complete negation of the previous curriculum, nor is it simply to turn the curriculum into a game, but to improve, extend or even transform the original curriculum. To make the curriculum more suitable for 
the development of young children, closer to the life of young children, so that the spirit and concept of the game penetrate into all aspects of children's daily activities, and the ultimate and core purpose is for the comprehensive development of children's physical and mental health.

\subsection{Study on the Basic Characteristics of Gamification in Kindergarten Curriculum}

Among the existing research results, there are not many research results that specifically study the basic characteristics of kindergarten curriculum gamification, and most of them combine the basic characteristics of kindergarten curriculum gamification with its basic connotation and educational value to research. Exploring the basic characteristics of kindergarten curriculum gamification from different perspectives can lead to different insights. On the whole, Zhang, Q. X. (2005) elaborated that the kindergarten curriculum gamification has the characteristics of comprehensiveness, generation, integration and so on [7]. However, Tao, J. L. and Fan, C. Y. (2016) proposed that curriculum gamification not only has the characteristics of diversification, interesting and game, but also has the characteristics of suitability, autonomy, generation and so on [8]. From the process point of view, Ma, Z. L. (2017) believes that kindergarten curriculum gamification is characterized by making children feel physically and mentally pleasant in the process of teaching, having absolute right to speak, and also making children highly coordinate with teachers' teaching arrangements, which is conducive to achieving teaching objectives [9]. Starting from the field of art, Cao, D. F. (2018) points out that kindergarten curriculum gamification has the characteristics of gameplay, interesting, situational, subjectivity, pleasure and so on [10].

\subsection{Study on the Educational Value of Gamification in Kindergarten Curriculum}

Zou, J. Y. (2018) put forward that kindergarten curriculum gamification has three great values: first, it fits the physical and mental development of children; second, it promotes the comprehensive development of children; third, curriculum and games complement each other [11]. Song, J. Y. (2007) and Ma, Z. L. (2017) and other scholars have shown that the core value of kindergarten curriculum gamification is for the healthy development of children's body and mind. The former through the study of kindergarten music curriculum gamification found that curriculum gamification is conducive to improve children's imagination, promote children's intellectual development, enrich children's cognitive ability, and enable children to enjoy learning easily and happily [12]. The latter shows that curriculum gamification can enrich children's growth experience, benefit children's cognitive ability and benefit their physical and mental development [9]. Zhao, K. X. (2018) and Lu, Y. J. (2019) believe that curriculum gamification can not only help children better recognition and understand the 
surrounding environment through the form of games, but also enable children to get physical exercise and rich learning experience in the process of participation. In addition, it can promote the development of good relationship between teachers and children, and cultivate the tacit understanding between children and children. Moreover, Cao, D. F. (2018), starting from the field of art, believes that gamification of curriculum is to make game as the form of curriculum, make game spirit become the soul of curriculum, and give full play to the instrumental and ontological value of game [10].

\subsection{Study on the Existing Predicament of Gamification in Kindergarten Curriculum}

The kindergarten curriculum gamification does not simply turn the curriculum into games, nor does it simply intersperse several games session in the teaching activities. Yu, Y. P. (2015) emphasizes that curriculum gamification should be considered as a long-term, systematic quality project [1]. It is necessary to avoid misunderstanding of curriculum gamification. Otherwise, it will not only be detrimental to the development of young children, but also not conducive to the improvement of the quality of early childhood education. By combing relevant literature, there are different aspects of the problem in the current theoretical research or practical exploration of kindergarten curriculum gamification. Some scholars put forward several problems in the process of kindergarten curriculum gamification: one is the environment setting on the departure from the game elements; second, the lack of game literacy in course construction; third, there are deviations in parents' cognition [13]. Moreover, the practice process of curriculum gamification still has some problems such as vague goals, monotonous forms and low efficiency [14].

However, some scholars have found through experiments that there are different degrees of problems in the teaching status and practice status of the implementation of curriculum gamification in the social field of kindergartens. Judging from the current teaching situation, the development of education in the kindergarten social field is unbalanced, and the curriculum objectives dimension are not clear, and the teaching design and teaching methods need to be improved. From the practical situation, there are two major problems in the teaching activities in this field: unreasonable use of games and inappropriate guidance from teachers [5]. Ding, Y. L. (2015) found through research that in the course of practice, curriculum gamification does not correctly grasp the relationship between the curriculum and the game, and the form of teaching and the construction of the curriculum lack the suitability for young children [15]. Ge, C. H. (2019) through the study of Zhang Xuemen's educational thoughts, and then contact with the present, it is proposed that the current curriculum gamification exists teaching copied the teaching material, lack of flexibility in practice, lack of training for teachers and other problems, which is not conducive to the development of young children [16]. 


\subsection{Study on the Advance Strategy of Gamification in Kindergarten Curriculum}

Some scholars believe that the essence of curriculum gamification is more of a concept of curriculum reform. Shi, Y. H. (2019) pointed out that in order to promote the game of kindergarten curriculum, teachers must start with changing the concept of education and teaching, combine the game with the curriculum system, conduct regular seminars and exchanges, and put the curriculum gamification into practice [17]. Cao, Y. L. (2016) shows that in order to change the current exists the phenomenon of utilitarianism in curriculum gamification construction, the key is the change of concept. Through "human affairs be kind and helpful to each other" $\rightarrow$ "multi-dimensional interaction" $\rightarrow$ "horizon fusion", let the curriculum gamification is more suitable for the development of young children [18]. In addition, Kong, S. T. (2017) and Guo, D. Y. (2018) believe that correctly handling the relationship between curriculum and games is the prerequisite for the smooth implementation of curriculum gamification. The former proposes that the combination of education through entertainment between the course and the game is the key point of curcululum gamification. In addition, it is also necessary to pay attention to the organic combination of teaching content, evaluation mechanism, life experience and other with the games [19]. The latter proposed that the construction of curriculum gamification should be based on young children, not only organic integration of courses and games, flexible use of evaluation mechanisms, but also focus on improving the overall quality of overall teacher [20]. However, Ding, Y. L. (2015) believes that we can start from the teacher level, improve the construction model and evaluation system of curriculum gamification, correctly handle the relationship between curriculum and games, clarify the essence of curriculum gamification and its future direction, and help the curriculum gamification further development [15].

Kindergarten curriculum gamification's boosting strategy needs to closely focus on the child's dominant position, starting from the existing conditions of the kindergarten and adapting to local conditions. Regardless of what kind of propulsion strategy, its core should focus on the development of young children. Let the children can "learn from play" and "play from learn" in a relaxed and happy atmosphere, so that to give attention to both the course and the game, let the course and the game can be organic integration. Only the curriculum gamification that is suitable for young children is the best.

\section{Research Deficiency and Prospect}

In summary, throughout the current research status of kindergarten curriculum gamification in China, the state's emphasis on kindergarten curriculum gamification is growing. And the existing research has achieved certain results on the basic connotation, basic characteristics, educational value, existing predicament and promotion strategy of kindergarten curriculum gamification. However, by combing the existing literature, it is found that most of the journal articles are 
from the frontline teachers, and there are few authoritative works and core literatures. The connotation, characteristics and value of the kindergarten curriculum gamification have not been clearly defined, and there are many studies but tend to be theoretical level and lack systematic research. It can be summarized in the following aspects:

- First, the research subject is single, and multi-dimensional research subject participation is urgently needed. At present, most researchers about kindergarten curriculum gamification are front-line managers and educators, especially kindergarten teachers. In contrast, there are only a few studies by other scholars. To some extent, it reflects the fact that kindergarten curriculum gamification is the actual demand of front-line teachers in their real work, and it also shows that other scholars do not attach enough importance to and participate in this aspect. Therefore, in future related research on kindergarten curriculum gamification, we can consider planning subjects, holding special academic meetings and appropriately extending the research cycle and other ways to attract researchers with strong scientific research level or even experts and scholars in academia to join the research team.

- Second, the research perspective is narrow, so it is urgent to draw lessons from the multi-disciplinary research paradigm. It is the nature of young children to love to play and to move. As the basic activities of young children, the game can satisfy the children's innermost desires and meet the children's special physical and mental development rules. It is also the most natural, direct and effective way for young children to learn. Curriculum gamification is not the only way to reform the kindergarten curriculum, but it is the necessary channel to adapt to the development of the times and follow the pace of society. Although research on "Game" in the field of preschool education has always been a hot topic in the education field, for now the research on kindergarten curriculum gamification under the guidance of new ideas is still relatively rare. According to the existing literature of CNKI, there are only 122 valid documents retrieved by search condition title "kindergarten curriculum gamification". Therefore, there is still a lot of space for research on the kindergarten curriculum gamification, and it is urgent for researchers to carry out different research from multiple dimensions.

- Thirdly, the depth of research is insufficient and systematic research results are urgently needed. In the available literature, most of them are published in general journals, while there are very few core journals and master's dissertations, and none of the doctoral dissertations can be found. From the perspective of research content, there are few articles that specifically discuss the connotation, value, characteristics and current situation of kindergarten curriculum gamification. Although most of the studies involve the promotion strategies of kindergarten curriculum gamification, most of the studies are only superficial and the researchers have strong subjective limitations, so the strategies mentioned are not suitable for wide use. Therefore, the study of 
kindergarten curriculum gamification should be carried out from theory to practice and then practice to test theory, so as to make the theory and practice cycle, so that the theory can be sublimated in practice and the practice can be improved in theory, and continuously promote the in-depth study of kindergarten curriculum gamification.

\section{Acknowledgements}

This research was supported by Research Achievements of the Graduate Innovation Fund Project of Gannan Normal University in Jiangxi Province, China (2018) 'Empirical Study on the Influence of Teachers' Autonomous Support and Family Education on Children's Learning Quality" (Project No. YCX18A010), 2019 China Jiangxi Young Marxist Theory Research Innovation Project Funding Project "Research on Reading Teaching of Children's Picture Book Based on Deep Learning-Taking the Large Class of S Kindergarten in Ganzhou City, Jiangxi Province as an Example" (Project No. 19QM80).

\section{Conflicts of Interest}

The author declares no conflicts of interest regarding the publication of this paper.

\section{References}

[1] Yu, Y.P. (2015) Curriculum Gamification: Only to Be Closer to the Children's Mind. China Education News Network. http://www.jyb.cn/china/gnxw/201506/t20150628_627873.html

[2] Shuai, J.R. (2016) Organizational Strategies of Kindergarten Curriculum Gamification. Inner Mongolia Education, 26, 14.

http://xueshu.baidu.com/usercenter/paper/show?paperid=f27dc3852ba6d57765aec0 91b20afbd3\&site=xueshu_se

[3] Song, M. (2018) Kindergarten Curriculum Gamification: The Return of Playing Spirit. Journal of Shaanxi Xueqian Normal University, 1, 35-38.

http://qikan.cqvip.com/Qikan/Article/Detail?id=674345937\&from=Qikan_Search_I $\underline{\text { ndex }}$

[4] Zhu, Z.H. (2018) The Connotation and Value of Gamification of Kindergarten Curriculum. Journal of Qiqihar Junior Teachers' College, 5, 96-98.

http://qikan.cqvip.com/Qikan/Article/Detail?id=676382406\&from=Qikan_Search_I $\underline{\text { ndex }}$

[5] Sun, B. (2017) Action Research on the Implementation of Curriculum Gamification in Kindergarten Social Field. Master's Thesis, Liaoning Normal University, Liaoning. http://cdmd.cnki.com.cn/Article/CDMD-10165-1017116420.htm

[6] Zhang, Z.Z. (2018) Investigation and Research on the Professional Development Present Situation of Rural Preschool Teachers under the Background of Curriculum Gamification-A Case Study of Y City. Master's Thesis, Qinghai Normal University, Qinghai. http://cdmd.cnki.com.cn/Article/CDMD-10746-1018242001.htm

[7] Zhang, Q.X. (2005) Basic Characteristics and Organizational Strategies of Gamification Kindergarten Course. Early Childhood Education, 6A, 10-11.

http://qikan.cqvip.com/Qikan/Article/Detail?id=15683699\&from=Qikan_Search_In 
$\underline{\text { dex }}$

[8] Tao, J.L. and Fan, C.Y. (2016) Kindergarten Curriculum Gamification Strategy. Jiangsu Early Childhood Education, 1, 6-9+23.

http://qikan.cqvip.com/Qikan/Article/Detail?id=74838969504849544849484854\&fr om=Qikan_Search_Index

[9] Ma, Z.L. (2017) Organizational Strategies of Kindergarten Curriculum Gamification. Ability and Wisdom, 10, 67. http://www.cnki.com.cn/Article/CJFDTOTAL-CAIZ201710056.htm

[10] Cao, D.F. (2018) Research on Curriculum Gamification in Kindergarten Art Field. Master's Thesis, Shandong Normal University, Jinan. http://cdmd.cnki.com.cn/Article/CDMD-10445-1018209492.htm

[11] Zou, J.Y. (2018) Curriculum Gamification, Kindergarten Courses Make the Move. Read and Write (Educational Teaching Journal), 9, 231.

[12] Song, J.Y. (2007) Music Curriculum Gamification Study in Kindergarten. Journal of Qinghai Normal University (Philosophy and Social Sciences Edition), 2, 145-147.

[13] Guo, J.J. (2018) Problems and Improvement Strategies in the Process of Children's Curriculum Gamification. Elite Teachers Online, 28, 56-57. http://www.cnki.com.cn/Article/CJFDTOTAL-MSZX201828036.htm

[14] Mei, C.T. (2016) Development of Kindergarten Sports Activities under the Background of Curriculum Gamification. Studies in Early Childhood Education, 8, 64-66.

[15] Ding, Y.L. (2015) Promotion Strategies of Kindergarten Curriculum Gamification. Studies in Early Childhood Education, 12, 64-66.

[16] Ge, C.H. (2019) Enlightenment of Zhang Xuemen's Educational Thought on Kindergarten Curriculum Gamification. Elite Teachers Online, 1, 49-50. http://www.cnki.com.cn/Article/CJFDTOTAL-MSZX201901032.htm

[17] Shi, Y.H. (2019) Study on the Implementation Strategies of Children's Curriculum Gamification. Contemporary Teaching Research Cluster, 4, 138. http://www.cnki.com.cn/Article/CJFDTOTAL-DDYC201904110.htm

[18] Cao, Y.L. (2016) Kindergarten-Based Understanding and Implementation Strategies of "Curriculum Gamification". Studies in Early Childhood Education, 12, 61-63.

[19] Guo, D.Y. (2018) Study on the Implementation Strategies of Children's Curriculum Gamification. People's Education, 17, 71-72.

http://qikan.cqvip.com/Qikan/Article/Detail?id=676200351\&from=Qikan_Search_I $\underline{\text { ndex }}$

[20] Kong, S.T. (2017) Promotion Strategies of Kindergarten Curriculum Gamification. West Leather, 8, 210. 